\title{
Blood Gases and Retinopathy of Prematurity: The ELGAN Study
}

\author{
Alisse K. Hauspurg ${ }^{\text {a }}$ Elizabeth N. Allred $^{\text {b-d }}$ Deborah K. Vanderveen ${ }^{e, f}$ \\ Minghua Chen ${ }^{g}$ Francis J. Bednarek ${ }^{h}$ Cynthia Cole ${ }^{i}$ Richard A. Ehrenkranz $^{a}{ }^{j}$ \\ Alan Leviton $^{\mathrm{b}, \mathrm{c}}$ Olaf Dammann ${ }^{\mathrm{b}, \mathrm{g}, \mathrm{k}}$ \\ a Yale University School of Medicine, New Haven, Conn., ${ }^{b}$ Neuroepidemiology Unit, Children's Hospital Boston, \\ cNeurology, Harvard Medical School, ${ }^{\mathrm{d} B i o s t a t i s t i c s, ~ H a r v a r d ~ S c h o o l ~ o f ~ P u b l i c ~ H e a l t h, ~ e ~ D e p a r t m e n t ~ o f ~}$ \\ Ophthalmology, Children's Hospital Boston, ${ }^{f}$ Harvard Medical School, and ${ }^{9}$ Division of Newborn Medicine, \\ Floating Hospital for Children at Tufts Medical Center, Boston, Mass., hivision of Neonatology, Department of \\ Pediatrics, UMass Memorial, Worcester, Mass., 'Division of Neonatology, Department of Pediatrics, Boston Medical \\ Center, Boston, Mass., j'Department of Pediatrics, Yale University School of Medicine, New Haven, Conn., USA; \\ kPerinatal Neuroepidemiology Unit, Hannover Medical School, Hannover, Germany
}

\section{Key Words}

Retinopathy of prematurity $\cdot$ Hypercapnia $\cdot$ Hyperoxemia $\cdot$

Acidemia $\cdot$ Extremely low gestational age

\begin{abstract}
Objective: This study tested the hypothesis that preterm infants who had a blood gas derangement on at least 2 of the first 3 postnatal days are at increased risk for more severe retinopathy of prematurity (ROP). Method: 1,042 infants born before 28 weeks' gestational age (GA) were included. An infant was considered to be exposed if his/her blood gas measure was in the highest or lowest quartile for GA on at least 2 of the first 3 postnatal days. Results: Multivariable models adjusting for confounders indicate that exposure to a $\mathrm{PCO}_{2}$ in the highest quartile predicts ROP (stage 3, 4 or 5: $\mathrm{OR}=1.6,95 \% \mathrm{Cl}=1.1-2.3$ ); zone 1: 2.0, 1.1-3.6; prethreshold/ threshold: 1.9, 1.2-3.0; plus disease: 1.8, 1.1-2.9). Estimates are similar for a low $\mathrm{pH}$ for zone 1 (2.1, 1.2-3.8), prethreshold/ threshold $(1.8,1.1-2.8)$, but did not quite achieve statistical significance for ROP stage 3,4 , or $5(1.4,0.9-2.0)$ and plus disease (1.5, 0.9-2.4). $\mathrm{A} \mathrm{PaO}_{2}$ in the highest quartile for $\mathrm{GA}$ on at
\end{abstract}

\section{KARGER}

(c) 2010 S. Karger AG, Basel

Fax +41613061234 E-Mail karger@karger.ch www.karger.com www.karger.com/neo least 2 of the first 3 postnatal days was associated with a doubling of the risk of ROP in zone $1(2.5,1.4-4.4)$ and of prethreshold/threshold disease $(2.1,1.4-3.3)$, a $70 \%$ risk increase for plus disease $(1.7,1.04-2.8)$, while a $40 \%$ risk increase for ROP stage 3 or higher did not achieve statistical significance (1.4, 0.96-2.0). Conclusion: Infants exposed to high $\mathrm{PCO}_{2}$, low $\mathrm{pH}$ and high $\mathrm{PaO}_{2}$ appear to be at increased risk of more severe ROP.

Copyright $\odot 2010$ S. Karger AG, Basel

\section{Introduction}

More than half a century ago, prolonged exposure to high oxygen concentration was identified as an important contributor to retrolental fibroplasia, the potentially blinding disorder now known as retinopathy of prematurity (ROP) [1,2]. Despite efforts to reduce oxygen exposure, ROP remains a common disorder among low gestational age (GA) newborns [3-5].

\section{A.L. and O.D. contributed equally to this work.}

Prof. Olaf Dammann

Division of Newborn Medicine

Floating Hospital for Children at Tufts Medical Center

800 Washington St., Box 854, Boston, MA 02111 (USA)

Tel. +1 617636 0240, Fax +1 617636 3309, E-Mail odammann@ tuftsmedicalcenter.org 
As neonatologists try to achieve blood oxygen concentrations that minimize risks of damage to brain, lung and retina, controversy continues about how low blood oxygen levels can/should be without damaging any organ [6-9]. In this report, we explore the relationships between blood oxygen, carbon dioxide, and $\mathrm{pH}$ levels during the first 3 postnatal days and severe ROP in a contemporary cohort.

\section{Methods}

The ELGAN Study was designed to identify characteristics and exposures that increase the risk of structural and functional neurologic disorders in extremely low gestational age newborns (ELGANs) [10-16]. During the years 2002-2004, women delivering before 28 weeks' gestation at one of 14 participating institutions in 11 cities in 5 states were asked to enroll in the study. The enrollment and consent processes were approved by the individual institutional review boards.

Mothers were approached for consent either upon antenatal admission or shortly after delivery, depending on clinical circumstance and institutional preference. 1,249 mothers of 1,506 infants consented. A total of 464 of these infants either died, did not have blood gas assessments on at least 2 of the first 3 postnatal days, or did not have a retinal examination. The remaining 1,042 infants compose the sample for this report.

\section{Demographic and Pregnancy Variables}

After the infant's delivery, a trained research nurse interviewed each mother in her native language using a structured data collection and following procedures contained in a manual. Shortly after the mother's discharge, the research nurse reviewed the maternal chart using a second structured data collection form. The medical record was relied on for events following admission. The clinical circumstances that led to each maternal admission and ultimately to each preterm delivery were operationally defined using both data from the maternal interview and data abstracted from the medical record [14].

\section{Newborn Variables}

GA estimates were based on a hierarchy of the quality of available information. Most desirable were estimates based on the dates of embryo retrieval or intrauterine insemination or fetal ultrasound before the 14 th week (62\%). When these were not available, reliance was placed sequentially on a fetal ultrasound at 14 or more weeks (29\%), last menstrual period without fetal ultrasound (7\%), and GA recorded in the log of the neonatal intensive care unit (1\%). The birth weight Z-score is the number of standard deviations the infant's birth weight is above or below the median weight of infants at the same GA in a standard dataset [17].

\section{Placentas}

Placentas were placed in a sterile examination basin and transported to a sampling room. $82 \%$ of the samples were obtained within $1 \mathrm{~h}$ of delivery. The microbiologic and histologic procedures are described elsewhere in detail $[18,19]$.
Table 1. The values that define the highest and lowest quartiles of each blood gas displayed on the left on each day in each gestational age group

\begin{tabular}{llccc}
\hline \multirow{2}{*}{$\begin{array}{l}\text { Blood gas } \\
\text { day }\end{array}$} & \multirow{2}{*}{\begin{tabular}{l} 
Gestational age, weeks \\
\cline { 3 - 5 }
\end{tabular}} & $23-24$ & $25-26$ & 27 \\
\hline Lowest quartile & 1 & 40 & 42 & 40 \\
$\mathrm{PaO}_{2}, \mathrm{~mm} \mathrm{Hg}$ & 2 & 43 & 45 & 44 \\
& 3 & 43 & 45 & 43 \\
\hline Highest quartile & 1 & 152 & 145 & 143 \\
$\mathrm{PaO}_{2}$, mm Hg & 2 & 98 & 100 & 92 \\
& 3 & 103 & 95 & 93 \\
\hline Lowest quartile & 1 & 27 & 29 & 29 \\
$\mathrm{PCO}_{2}$, mm Hg & 2 & 33 & 35 & 35 \\
& 3 & 33 & 33 & 35 \\
\hline Highest quartile & 1 & 65 & 67 & 63 \\
$\mathrm{PCO}_{2}$, mm Hg & 2 & 60 & 64 & 60 \\
& 3 & 58 & 57 & 56 \\
\hline Lowest quartile & 1 & 7.15 & 7.20 & 7.22 \\
pH $^{2}$ & 2 & 7.14 & 7.17 & 7.22 \\
& 3 & 7.16 & 7.19 & 7.22 \\
\hline
\end{tabular}

\section{Blood Gases}

On postnatal days 1,2, and 3, we collected information about the lowest, modal, and highest $\mathrm{PaO}_{2}, \mathrm{PCO}_{2}$, and $\mathrm{pH}$. Only arterial blood was used for oxygen measurements (indicated by the ' $\mathrm{a}$ ' in $\mathrm{PaO}_{2}$ ). Measurements of $\mathrm{PCO}_{2}$ and $\mathrm{pH}$ were arterial except for 7 ELGANs on day 1, 15 on day 2, and 60 infants on day 3, all of whom had these measurements made on venous blood. We calculated quartiles of $\mathrm{PCO}_{2}$ and $\mathrm{pH}$ separately for arterial and venous measures, assigned a child's measure to the upper quartile based on whether her measure was arterial or venous, and combined the resulting dichotomous values.

In our sample, the blood gas measurement that defined the highest and lowest quartile varied by GA and by postnatal day (table 1). We therefore classified infants by whether or not their extreme value each day was in the extreme quartile for their GA (23-24, 25-26, and 27 weeks). Because an extreme measure on 1 day could reflect a transient event, we required that an infant be in the extreme quartile on at least 2 of the 3 days to be considered 'exposed' to such extremes.

Our not having blood gas measurements on all 3 of the first 3 postnatal days might be an example of informative missingness. In essence, children who did not have a blood gas on postnatal day 3 were more likely to be physiologically stable than infants who had a set of blood gas measurements that day. Children who did not have day 3 measurements are also much less likely than others to have postnatal day 2 measurements that are in any extreme quartile. We, therefore, considered it reasonable to assign these newborns to the group with non-extreme measurements on postnatal day 3. This allows us to include these children in this sample, and thereby avoids our inflating odds ratios inappropriately. 


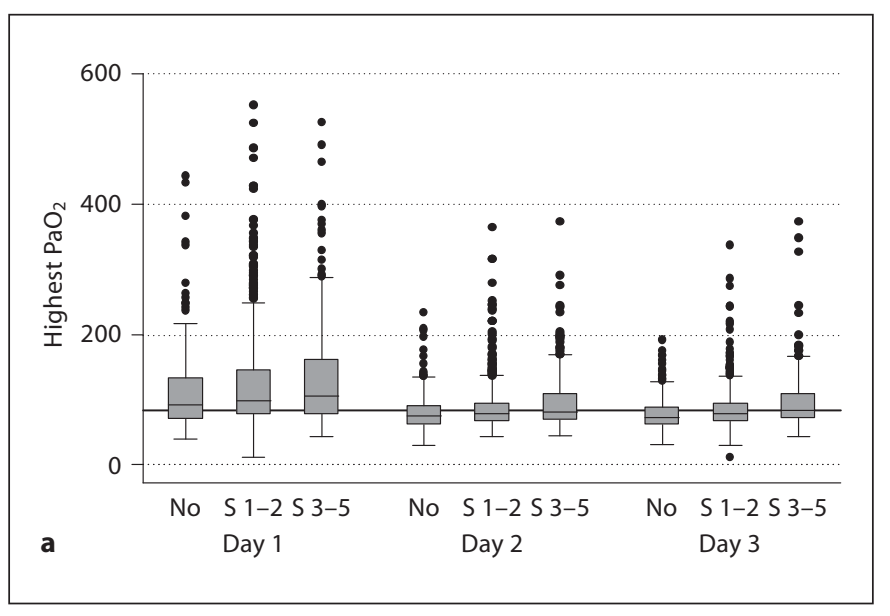

Fig. 1. Box-and-whisker plots of highest $\mathrm{PaO}_{2}$ (a), highest $\mathrm{PCO}_{2}$ (b), and lowest $\mathrm{pH}$ (c) on each postnatal day of infants with no ROP, stage 1-2 ROP, and stage 3-5 ROP. The median is indicated by the line closest to the middle of the box, while the top and bottom of the box indicate the 25 th and 75 th centiles. The dispersion of blood gases is indicated by the length of the vertical lines emanating from each box, as well as the black dots, which identify outliers.

We collected the minimum and maximum blood gas values each day. Because we cannot tell if extreme $\mathrm{pH}$ and $\mathrm{PCO}_{2}$ measurements are paired, we did not calculate base excess. We did not require any blood gases to be taken as per protocol. All measurements were taken at the discretion of the attending physician. Thus, there is no standardized frequency of blood gas measurements in this study.

\section{Eye Examinations}

Participating ophthalmologists helped prepare a manual and data collection form, and then participated in efforts to minimize observer variability. Definitions of terms were those accepted by the International Committee for Classification of ROP [20].

ELGAN ophthalmologists used indirect ophthalmoscopy. Only one of our sites used RetCam with any frequency. In keeping with guidelines [21], the first ophthalmologic examination was within the 31st to 33rd postmenstrual week. In accordance with follow-up examination guidelines, infants at high risk of ROP were examined weekly, while those with no ROP present at first examination were re-examined every $2-3$ weeks. Photographs were encouraged in case of doubt about classification. We did not include information about treatment because Early Treatment for
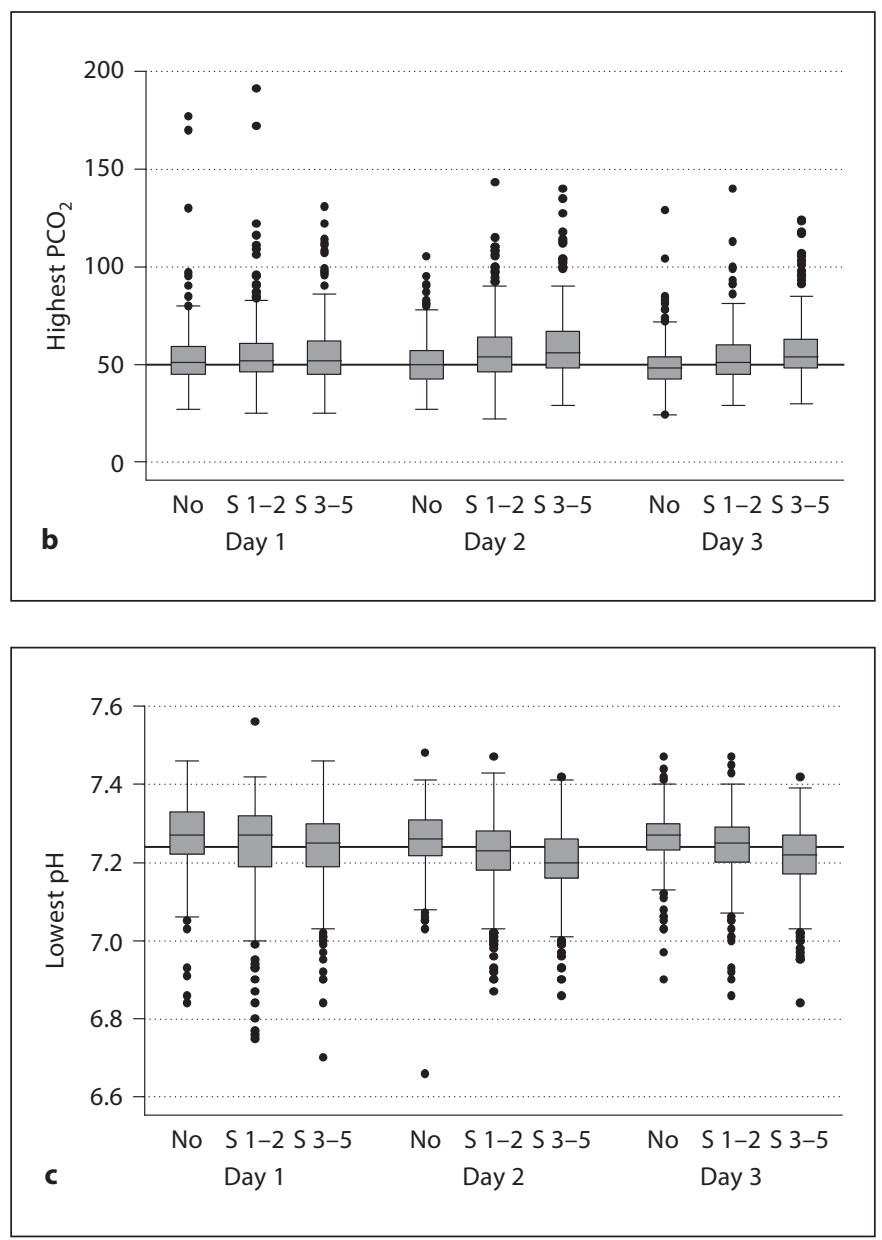

ROP (ETROP) guidelines, including suggested policy changes, were released during the recruitment phase [22].

Data Analysis

The generalized form of the null hypothesis we evaluated is that children who have a blood gas in an extreme quartile on 2 of the first 3 postnatal days are not at higher risk of severe ROP than children who did not have that blood gas extreme on 2 of the first 3 postnatal days. We evaluated five blood gas extremes (lowest quartile of $\mathrm{PaO}_{2}$, highest quartile of $\mathrm{PaO}_{2}$, lowest quartile of $\mathrm{PCO}_{2}$, highest quartile of $\mathrm{PCO}_{2}$, lowest quartile of $\mathrm{pH}$ ) in models that included the three of the other four blood gas extremes as well as other confounders. Confounders were selected by their association with a blood gas extreme and stage 3 or higher ROP, biologic plausibility or previous identification in the literature (table 2). All conditional logistic multivariable models included a hospital cluster term (to account for the possibility that infants born at a particular hospital are more like each other than like infants born at other hospitals) [23]. The contributions of relevant variables are presented as risk ratios with $95 \%$ confidence intervals.

In this sample, children who had a $\mathrm{PCO}_{2}$ in the highest quartile tended to have a $\mathrm{pH}$ in the lowest quartile more commonly 
Table 2. Distribution of ROP stage 3,4 or 5 and infants who had a blood gas extreme (defined as a $\mathrm{PaO}_{2}, \mathrm{PCO}_{2}$, or $\mathrm{pH}$ in the highest or lowest quartile for gestational age on at least 2 of the first 3 postnatal days) listed at the top of each column on within strata of potential confounders, listed on the left (these are row percents)

\begin{tabular}{|c|c|c|c|c|c|c|c|}
\hline \multirow[t]{2}{*}{ Potential confounder } & \multicolumn{5}{|c|}{ Blood gas extreme } & \multirow{2}{*}{$\begin{array}{l}\text { ROP } \\
\text { stage } 3 \\
\text { or higher }\end{array}$} & \multirow{2}{*}{$\begin{array}{l}\text { Row } \\
\mathrm{n}\end{array}$} \\
\hline & $\begin{array}{l}\text { lowest } \\
\mathrm{PaO}_{2}\end{array}$ & $\begin{array}{l}\text { highest } \\
\mathrm{PaO}_{2}\end{array}$ & $\begin{array}{l}\text { lowest } \\
\mathrm{PCO}_{2}\end{array}$ & $\begin{array}{l}\text { highest } \\
\mathrm{PCO}_{2}\end{array}$ & $\begin{array}{l}\text { lowest } \\
\mathrm{pH}\end{array}$ & & \\
\hline \multicolumn{8}{|c|}{ Pre-pregnancy Body Mass Index } \\
\hline$<18.5$ & 22 & 19 & 25 & 28 & 28 & 30 & 67 \\
\hline$\geq 18.5,<25$ & 24 & 19 & 22 & 22 & 20 & 30 & 514 \\
\hline$\geq 25,<30$ & 18 & 27 & 21 & 18 & 21 & 32 & 204 \\
\hline$\geq 30$ & 22 & 22 & 23 & 24 & 25 & 35 & 207 \\
\hline \multicolumn{8}{|l|}{ Aspirin } \\
\hline Yes & 32 & 15 & 23 & 23 & 25 & 49 & 43 \\
\hline No & 21 & 22 & 22 & 22 & 22 & 30 & 955 \\
\hline \multicolumn{8}{|l|}{ Highest $\mathrm{WBC}^{1}$} \\
\hline$>20,000$ & 26 & 21 & 19 & 21 & 16 & 38 & 210 \\
\hline$\leq 20,000$ & 21 & 21 & 23 & 22 & 23 & 30 & 812 \\
\hline \multicolumn{8}{|l|}{ Initiator of delivery } \\
\hline Preeclampsia & 26 & 28 & 22 & 32 & 28 & 38 & 138 \\
\hline Fetal indication & 38 & 18 & 11 & 31 & 36 & 36 & 45 \\
\hline Spontaneous & 21 & 20 & 23 & 20 & 20 & 31 & 857 \\
\hline \multicolumn{8}{|l|}{$\begin{array}{l}\text { Decidual hemorrhage/fibrin } \\
\text { deposition }\end{array}$} \\
\hline Yes & 20 & 14 & 20 & 23 & 22 & 37 & 158 \\
\hline No & 22 & 22 & 22 & 21 & 21 & 31 & 797 \\
\hline \multicolumn{8}{|l|}{ Gestational age } \\
\hline 23-24 weeks & 21 & 20 & 22 & 24 & 23 & 51 & 255 \\
\hline $25-26$ weeks & 22 & 21 & 22 & 20 & 20 & 33 & 488 \\
\hline 27 weeks & 22 & 22 & 22 & 23 & 23 & 13 & 299 \\
\hline \multicolumn{8}{|l|}{ Birth weight Z-score ${ }^{2}$} \\
\hline$<-2$ & 23 & 22 & 25 & 27 & 39 & 45 & 64 \\
\hline$\geq-2,<-1$ & 28 & 27 & 25 & 33 & 28 & 41 & 150 \\
\hline$\geq-1$ & 21 & 20 & 21 & 20 & 19 & 29 & 828 \\
\hline Overall row percent & 22 & 21 & 22 & 22 & 22 & 32 & \\
\hline Maximum column number & 227 & 221 & 230 & 229 & 225 & 331 & 1,042 \\
\hline
\end{tabular}

${ }^{1}$ White blood cell count (WBC) within the interval before delivery to $48 \mathrm{~h}$ post-delivery.

${ }^{2}$ Birth weight Z-scores based on standard of Yudkin et al. [17].

than expected if their co-occurrence was independent of the other (data not shown). As expected, models with both of these variables provided evidence that these two variables shared discriminating information. Consequently, we present two multivariable models for each ROP classification. Model 1 includes a variable for high $\mathrm{PCO}_{2}$, but not for low $\mathrm{pH}$. Model 2, on the other hand, has a variable for low $\mathrm{pH}$, but not for high $\mathrm{PCO}_{2}$.

We summarize some of our data with box-and-whisker displays of the central tendency and dispersion of blood gases in ROP groups (fig. 1). The central tendency is indicated by the line close to the middle of the box, which is the median, and by the top and bottom of each box, which indicate the 25 th and 75 th centiles. The dispersion of blood gases is indicated by the length of the vertical lines that emanate from the box, as well as by the black dots, which identify outliers.

Blood Gases and Retinopathy of Prematurity: The ELGAN Study

\section{Results}

On each postnatal day, we observed an upward trend for highest oxygen and carbon dioxide with increasing ROP severity (fig. 1). Infants with more severe ROP had lower $\mathrm{pH}$ levels on each postnatal day.

\section{Identification of Confounders (table 2)}

We created table 2 to identify confounders, those variables associated with a blood gas extreme, and with stage 3 or higher ROP. Our comments about the tables are limited to potential confounders. 
Table 3. Percentages of children classified by their ROP status (on the left) who satisfied the blood gas criterion at the top of each column (these are row percents)

\begin{tabular}{|c|c|c|c|c|c|c|}
\hline \multirow{2}{*}{$\begin{array}{l}\text { ROP } \\
\text { severity }\end{array}$} & \multicolumn{6}{|c|}{ Blood gas extreme } \\
\hline & $\begin{array}{l}\text { lowest } \\
\text { quartile } \\
\mathrm{PaO}_{2}\end{array}$ & $\begin{array}{l}\text { highest } \\
\text { quartile } \\
\mathrm{PaO}_{2}\end{array}$ & $\begin{array}{l}\text { lowest } \\
\text { quartile } \\
\mathrm{PCO}_{2}\end{array}$ & $\begin{array}{l}\text { highest } \\
\text { quartile } \\
\mathrm{PCO}_{2} \\
\end{array}$ & $\begin{array}{l}\text { lowest } \\
\text { quartile } \\
\mathrm{pH}\end{array}$ & $\begin{array}{l}\text { row } \\
n\end{array}$ \\
\hline \multicolumn{7}{|l|}{ Stage 3,4 , or 5} \\
\hline Yes & 20 & 27 & 24 & 26 & 25 & 331 \\
\hline No & 23 & 19 & 21 & 20 & 20 & 711 \\
\hline \multicolumn{7}{|l|}{ Zone 1} \\
\hline Yes & 20 & 37 & 19 & 30 & 35 & 89 \\
\hline No & 22 & 20 & 22 & 21 & 20 & 953 \\
\hline \multicolumn{7}{|c|}{ Prethreshold or threshold } \\
\hline Yes & 25 & 31 & 21 & 33 & 32 & 174 \\
\hline No & 21 & 19 & 22 & 20 & 20 & 868 \\
\hline \multicolumn{7}{|l|}{ Plus disease } \\
\hline Yes & 28 & 28 & 22 & 36 & 31 & 134 \\
\hline No & 21 & 20 & 22 & 20 & 20 & 908 \\
\hline Overall & 22 & 21 & 22 & 22 & 22 & \\
\hline Column number & 227 & 221 & 230 & 229 & 225 & 1,042 \\
\hline
\end{tabular}

Maternal consumption of aspirin was associated with both high and low extremes of $\mathrm{PaO}_{2}$ as well as with stage 3 or higher ROP. Infants whose mother presented with preeclampsia were at increased risk of hypercapnia and severe (i.e. stages 3, 4 and 5) ROP, while newborns delivered for fetal indications were at increased risk of hypoxemia, hypercapnia and acidemia, as well as severe ROP.

Decidual hemorrhage or fibrin deposition was associated with a small risk increase for severe ROP, but not with blood gas extremes.

Newborns in the lowest birth weight Z-score category (i.e. $<-2$ ) were at the highest risk of acidemia and stage 3 or higher ROP. Although the risk of severe ROP increased dramatically with progressively lower GA, blood gas extremes did not (largely because we defined the boundaries for blood gas extremes within GA groups) (see table 1).

We did not see an effect of sex on ROP risk or on the association between blood gases and ROP.

ROP Severity Classifications and Blood Gases (table 3)

Infants with stage 3 or higher ROP were more likely than their peers to be exposed to a high $\mathrm{PaO}_{2}$. Further, infants with plus disease were more likely than their peers to be exposed to a high $\mathrm{PCO}_{2}$ or low $\mathrm{pH}$. Stratifying newborns by the presence/absence of zone 1 or prethreshold/ threshold disease resulted in even more prominent differences in hyperoxemia frequency, as well as prominent differences in frequencies of hypercapnia and acidemia. This increased difference is probably due to the fact that 'stage 3 or higher' includes ROP in all zones, thereby diluting the effect.

\section{Multivariable Analyses (table 4)}

After adjustment for confounders, our multivariable models indicated several significant relationships between blood gas extremes and ROP, which were more prominent when ROP was dichotomized by zone or prethreshold/threshold than by stage. First, higher arterial $\mathrm{O}_{2}$ levels were significantly associated with zone 1, preand threshold ROP, and the presence of plus disease, while the association with stage 3 or higher disease did not reach statistical significance (both models). Second, high $\mathrm{PCO}_{2}$ levels were invariably significantly associated with increased risk of ROP stage 3 or higher, zone 1, prethreshold and threshold ROP and the presence of plus disease (model 1). Third, very similar effects were present with exposure to low $\mathrm{pH}$ (model 2).

\section{Discussion}

This is the first large-scale epidemiologic study of the relationship between blood gas extremes and ROP risk in ELGANs. Our main finding is that high blood concentra- 
Table 4. Odds ratios ${ }^{1}$ (and 95\% CI) of the association between blood gas extremes (defined as a blood gas measure in the highest or lowest quartile for gestational age) and the risk of ROP (the referent group for each set of analyses consists of all children who did not have the ROP classification listed at the top of each set of columns)

\begin{tabular}{|c|c|c|c|c|}
\hline \multirow[t]{2}{*}{ Blood gas } & \multicolumn{2}{|l|}{ Stage 3,4 , or 5} & \multicolumn{2}{|l|}{ Zone 1} \\
\hline & model 1 & model 2 & model 1 & model 2 \\
\hline Lowest $\mathrm{PaO}_{2}$ & $0.9(0.6,1.4)$ & $1.0(0.7,1.5)$ & $0.6(0.3,1.1)$ & $0.6(0.3,1.2)$ \\
\hline Highest $\mathrm{PaO}_{2}$ & $1.4(0.95,2.0)$ & $1.4(0.96,2.0)$ & $2.5(1.5,4.5)$ & $2.5(1.4,4.4)$ \\
\hline Lowest $\mathrm{PCO}_{2}$ & $0.8(0.6,1.2)$ & $0.8(0.6,1.2)$ & $0.7(0.4,1.5)$ & $0.7(0.4,1.4)$ \\
\hline Highest $\mathrm{PCO}_{2}$ & $1.6(1.1,2.3)$ & - & $2.0(1.1,3.6)$ & - \\
\hline Lowest $\mathrm{pH}$ & - & $1.4(0.9,2.0)$ & - & $2.1(1.2,3.8)$ \\
\hline \multirow[t]{2}{*}{ Blood gas } & \multicolumn{2}{|c|}{ Prethreshold or threshold } & \multicolumn{2}{|l|}{ Plus disease } \\
\hline & model 1 & model 2 & model 1 & model 2 \\
\hline Lowest $\mathrm{PaO}_{2}$ & $1.1(0.7,1.7)$ & $1.1(0.7,1.8)$ & $1.4(0.9,2.3)$ & $1.5(0.9,2.4)$ \\
\hline Highest $\mathrm{PaO}_{2}$ & $2.1(1.3,3.3)$ & $2.1(1.4,3.3)$ & $1.7(1.02,2.7)$ & $1.7(1.04,2.8)$ \\
\hline Lowest $\mathrm{PCO}_{2}$ & $0.8(0.5,1.3)$ & $0.8(0.5,1.3)$ & $0.8(0.5,1.4)$ & $0.8(0.5,1.4)$ \\
\hline Highest $\mathrm{PCO}_{2}$ & $1.9(1.2,3.0)$ & - & $1.8(1.1,2.9)$ & - \\
\hline Lowest $\mathrm{pH}$ & - & $1.8(1.1,2.8)$ & - & $1.5(0.9,2.4)$ \\
\hline
\end{tabular}

\footnotetext{
${ }^{1}$ All models are adjusted for maternal Body Mass Index $>30$, maternal use of aspirin during pregnancy, WBC $>20,000$ within $48 \mathrm{~h}$ of delivery, delivery for preeclampsia or fetal indication, decidual hemorrhage/fibrin deposition in placenta, gestational age (23-24, 25-26, 27 weeks) and birth weight $Z$-score $<-1$, definite early sepsis, definite late sepsis and all of the other blood gas extremes in the model. These models include a hospital cluster term to account for the possibility that infants born at a particular hospital are more like each other than like infants born at other hospitals.
}

tions of carbon dioxide and oxygen, and low blood $\mathrm{pH}$ in the first 3 postnatal days are significantly associated with an increased risk of severe ROP. These relationships remain statistically significant after adjustment for each of the other blood gases, as well as non-blood gas confounders.

Low GA and low birth weight are the strongest risk factors for ROP [3, 4]. Other known antecedents include low insulin-like growth factor 1 [24], varying vascular endothelial growth factor levels [25], systemic infection [26], inflammation [27], and genetic predisposition [28, 29]. Intraventricular hemorrhage appears to be associated with ROP, probably via shared risk factors [30, 31].

Hypercarbia and acidosis increase retinal neovascularization in animal models $[32,33]$. The presumed sequence is that hypercarbia promotes vessel dilation, which leads to increased oxygenation and increased blood flow, which in turn contributes to abnormal retinal vascularization [5].

Prior smaller clinical studies yielded inconsistent results $[34,35]$. In a study of 91 mechanically-ventilated in- fants of mean GA 29 weeks, a measurement of hypercarbia or hypocarbia on the first 3 postnatal days was not associated with an increased risk of ROP [35]. The authors suggested that cumulative exposure integrated over time might be a better way to capture potentially adverse events. Similar 'negative' results were found in another underpowered study, of 25 infants less than 30 weeks GA, in which neither carbon dioxide tension nor duration of hypo-/hypercarbia correlated with ROP [36]. Investigators of both studies suggested further investigation in larger cohorts.

In contrast to the above studies, we defined exposure as a blood gas measure in the highest or lowest quartile for GA on 2 of the first 3 postnatal days, rather than using a mean value or an upper limit. In this way, we are better able to perform risk analyses, while internally adjusting for GA.

In our study the infants exposed to $\mathrm{PCO}_{2}$ values in the highest quartile for their GA experienced carbon dioxide levels that exceed those defined as hypercarbia in previous studies [35]. In contrast, we found that a $\mathrm{pH}$ in the 
lowest quartile was associated with an increased risk of severe ROP.

Finally, we found that exposure to higher arterial oxygen levels in the first 3 postnatal days is associated with more severe ROP. This is consistent with previous studies and current clinical practice advocating the benefits of lower blood oxygen saturation during the first few weeks of life $[37,38]$. Further, lowering oxygen alarm set-points appears to lead to a decreased risk of severe ROP according to a structured formal review performed by our own group [39], and in recently published studies of policy changes [40-43]. This is currently the topic of ongoing randomized trials.

Our study included 1,042 ELGANs, of whom 800 (77\%) developed stage 1 or higher ROP, 331 (32\%) developed stages 3-5 ROP, 89 (9\%) developed zone 1 ROP, and 174 (17\%) developed prethreshold/threshold disease. Compared to previous studies with samples of fewer than 100 infants, this is an appreciable increase in sample size, and an appreciable increase in power. While most prior studies did not fully address confounding variables, we created multivariable models adjusting for a host of confounders. Consequently, our findings have the potential to improve our understanding of the relationship between blood gas extremes and severity of ROP.

The weaknesses of our study are those of all observational studies. Further, we assume that a blood gas derangement on 2 of the first 3 postnatal days constitutes an 'exposure'. We used this operationalized definition since we had no access to continuous blood gas measurements. Thus, we did not see any way of modeling fluctuations of blood gases in a consistent and thus meaningful fashion. Finally, we are unable to differentiate between respiratory and metabolic acidosis, a clinically relevant distinction that might deserve further investigation.

In light of the biologic plausibility of our findings, we suggest that blood-gas-associated ROP risk be considered in discussions of clinical practice. While oxygen saturation has dominated most of the recent ROP literature, the role of hypercarbia and acidosis in severe ROP may warrant further clinical consideration and study. This is especially important in light of recommendations about the safety and efficacy of 'permissive hypercarbia' [44]. Our findings, however, justify concerns raised in current discussions [45].

\section{Conclusion}

In summary, we found that repeatedly high blood concentrations of oxygen and carbon dioxide and low blood $\mathrm{pH}$ are associated with increased risk of severe ROP. Further studies might help better characterize the relationships of oxygenation, ventilation and acidosis with risk of ROP development in ELGANs.

\section{Acknowledgements}

This research was supported by a cooperative agreement with the National Institute of Neurological Disorders and Stroke (5U01NS040069-05), a grant from the National Eye Institute (1R21EY019253-01), a program project grant from the National Institute of Child Health and Human Development (NIH-P30HD-18655), a Yale University School of Medicine Student Research Fellowship, and the Richard Saltonstall Charitable Foundation.

\section{References}

1 Campbell K: Intensive oxygen therapy as a possible cause of retrolental fibroplasia: a clinical approach. Med J Aust 1951;2:48-50.

$\checkmark 2$ Patz A, Hoeck LE, De La Cruz E: Studies on the effect of high oxygen administration in retrolental fibroplasia. I. Nursery observations. Am J Ophthalmol 1952;35:1248-1253.

-3 Gibson DL, Sheps SB, Uh SH, Schechter MT, McCormick AQ: Retinopathy of prematurity-induced blindness: birth weight-specific survival and the new epidemic. Pediatrics 1990;86:405-412.

4 Palmer EA, Flynn JT, Hardy RJ, et al: Incidence and early course of retinopathy of prematurity. The Cryotherapy for Retinopathy of Prematurity Cooperative Group. Ophthalmology 1991;98:1628-1640.
5 McColm JR, Fleck BW: Retinopathy of prematurity: causation. Semin Neonatol 2001;6 453-460.

6 Cole CH, Wright KW, Tarnow-Mordi W, Phelps DL, Pulse Oximetry Saturation Trial for Prevention of Retinopathy of Prematurity Planning Study Group: Resolving our uncertainty about oxygen therapy. Pediatrics 2003;112:1415-1419.

$\checkmark 7$ Anderson CG, Benitz WE, Madan A: Retinopathy of prematurity and pulse oximetry: a national survey of recent practices. J Perinatol 2004;24:164-168.
8 Wright KW, Sami D, Thompson L, Ramanathan R, Joseph R, Farzavandi S: A physiologic reduced oxygen protocol decreases the incidence of threshold retinopathy of prematurity. Trans Am Ophthalmol Soc 2006;104: 78-84.

$\checkmark 9$ Vento M, Moro M, Escrig R, et al: Preterm resuscitation with low oxygen causes less oxidative stress, inflammation, and chronic lung disease. Pediatrics 2009; 124:e439e449.

10 Kuban K, Adler I, Allred EN, et al: Observer variability assessing US scans of the preterm brain: the ELGAN Study. Pediatr Radiol 2007;37:1201-1208. 
11 Laughon M, Bose C, Allred E, et al: Factors associated with treatment for hypotension in extremely low gestational age newborns during the first postnatal week. Pediatrics 2007; 119:273-280.

-12 O’Shea TM, Kuban KC, Allred EN, et al: Neonatal cranial ultrasound lesions and developmental delays at 2 years of age among extremely low gestational age children. Pediatrics 2008;122:e662-e669.

$\checkmark 13$ Kuban KC, Allred EN, O’Shea M, et al: An algorithm for identifying and classifying cerebral palsy in young children. J Pediatr 2008;153:466-472.

-14 McElrath TF, Hecht JL, Dammann O, et al: Pregnancy disorders that lead to delivery before the 28th week of gestation: an epidemiologic approach to classification. Am J Epidemiol 2008;168:980-989.

-15 Laughon M, Allred EN, Bose C, et al: Patterns of respiratory disease during the first two postnatal weeks in extremely premature infants. Pediatrics 2009;123:1124-1131.

-16 Olomu IN, Hecht JL, Onderdonk AO, Allred EN, Leviton A, Extremely Low Gestational Age Newborn Study Investigators: Perinatal correlates of Ureaplasma urealyticum in placenta parenchyma of singleton pregnancies that end before 28 weeks of gestation. Pediatrics 2009;123:1329-1336.

-17 Yudkin PL, Aboualfa M, Eyre JA, Redman CW, Wilkinson AR: New birthweight and head circumference centiles for gestational ages 24 to 42 weeks. Early Hum Dev 1987;15: 45-52.

-18 Onderdonk AB, Hecht JL, McElrath TF, et al: Colonization of second-trimester placenta parenchyma. Am J Obstet Gynecol 2008;199: 52.e1-52.e10.

19 Hecht J, Allred EN, Kliman H, et al: Histologic characteristics of singleton placentas delivered before the 28th week of gestation. Pathology 2008;40:372-376.

20 The International Committee for the Classification of the Late Stages of Retinopathy of Prematurity: An international classification of retinopathy of prematurity. II. The classification of retinal detachment. Arch Ophthalmol 1987;105:906-912.

-21 American Academy of Pediatrics. Section on Ophthalmology: Screening examination of premature infants for retinopathy of prematurity. Pediatrics 2001;108:809-811.
22 Early Treatment for Retinopathy of Prematurity Cooperative Group: Revised indications for the treatment of retinopathy of prematurity: results of the early treatment for retinopathy of prematurity randomized trial. Arch Ophthalmol 2003;121:1684-1694.

23 Begg MD, Parides MK: Separation of individual-level and cluster-level covariate effects in regression analysis of correlated data. Stat Med 2003;22:2591-2602.

24 Hellstrom A, Engstrom E, Hard AL, et al: Postnatal serum insulin-like growth factor I deficiency is associated with retinopathy of prematurity and other complications of premature birth. Pediatrics 2003;112:10161020.

25 Young TL, Anthony DC, Pierce E, Foley E Smith LE: Histopathology and vascular endothelial growth factor in untreated and diode laser-treated retinopathy of prematurity. J AAPOS 1997;1:105-110.

26 Bharwani SK, Dhanireddy R: Systemic fungal infection is associated with the development of retinopathy of prematurity in very low birth weight infants: a meta-review. J Perinatol 2008;28:61-66.

27 Dammann O, Brinkhaus MJ, Bartels DB, et al: Immaturity, perinatal inflammation, and retinopathy of prematurity: a multi-hit hypothesis. Early Hum Dev 2009;85:325-329.

28 Bizzarro MJ, Hussain N, Jonsson B, et al: Genetic susceptibility to retinopathy of prematurity. Pediatrics 2006;118:1858-1863.

29 Mohamed S, Schaa K, Cooper ME, et al: Genetic contributions to the development of retinopathy of prematurity. Pediatr Res 2009;65:193-197.

30 Procianoy RS, Garcia-Prats JA, Hittner HM et al: An association between retinopathy of prematurity and intraventricular hemorrhage in very low birthweight infants. Acta Paediatr Scand 1981;70:473-477.

-31 Lad EM, Nguyen TC, Morton JM, Moshfeghi DM: Retinopathy of prematurity in the United States. Br J Ophthalmol 2008;92:320-325.

-32 Holmes JM, Zhang S, Leske DA, Lanier WL: Carbon dioxide-induced retinopathy in the neonatal rat. Curr Eye Res 1998;17:608-616.

33 Zhang S, Leske DA, Lanier WL, Berkowitz BA, Holmes JM: Preretinal neovascularization associated with acetazolamide-induced systemic acidosis in the neonatal rat. Invest Ophthalmol Vis Sci 2001;42:1066-1071.
34 Saito Y, Omoto T, Cho Y, Hatsukawa Y, Fujimura M, Takeuchi T: The progression of retinopathy of prematurity and fluctuation in blood gas tension. Graefes Arch Clin Exp Ophthalmol 1993;231:151-156.

-35 Liao SL, Lai SH, Kuo CY: Effect of carbon dioxide tension in the first three days of life on the development of retinopathy of prematurity. Chang Gung Med J 2000;23:755-760.

>36 Gellen B, McIntosh N, McColm JR, Fleck BW: Is the partial pressure of carbon dioxide in the blood related to the development of retinopathy of prematurity? Br J Ophthalmol 2001;85:1044-1045.

37 Tin W: Oxygen therapy: 50 years of uncertainty. Pediatrics 2002;110:615-616.

38 Higgins RD, Bancalari E, Willinger M, Raju TN: Executive summary of the workshop on oxygen in neonatal therapies: controversies and opportunities for research. Pediatrics 2007;119:790-796.

-39 Chen ML, Guo L, Dammann CE, Dammann O: High or low oxygen saturation and severe retinopathy of prematurity: a meta-analysis. Pediatrics 2010;125:e1483-e1492.

40 Chow LC, Wright KW, Sola A, CSMC Oxygen Administration Study Group: Can changes in clinical practice decrease the incidence of severe retinopathy of prematurity in very low birth weight infants? Pediatrics 2003;111:339-345.

-41 Vanderveen DK, Mansfield TA, Eichenwald EC: Lower oxygen saturation alarm limits decrease the severity of retinopathy of prematurity. J AAPOS 2006;10:445-448.

-42 Sears JE, Pietz J, Sonnie C, Dolcini D, Hoppe $\mathrm{G}$ : A change in oxygen supplementation can decrease the incidence of retinopathy of prematurity. Ophthalmology 2009;116:513518.

43 Finer N, Leone T: Oxygen saturation monitoring for the preterm infant: the evidence basis for current practice. Pediatr Res 2009; 65:375-380

44 Miller JD, Carlo WA: Safety and effectiveness of permissive hypercapnia in the preterm infant. Curr Opin Pediatr 2007;19:142144.

45 Jankov RP, Tanswell AK: Hypercapnia and the neonate. Acta Paediatr 2008;97:15021509 . 